\title{
Research on Accelerating the Development and Construction of Urbanization in Aksu Prefecture
}

\author{
Guan Wenting, Zhu Xiaoling \\ College of economics and management Tarim University, Alar, Xinjiang, 843300
}

Keywords: urbanization construction/Aksu area/proposal

\begin{abstract}
In recent years, Xinjiang has vigorously promoted the construction of new urbanization, the four prefectures in south Xinjiang have proposed measures to build 100 small towns, hoping to speed up the transformation of old urban areas. Aksu area, as a typical example of urbanization in southern Xinjiang, is slow, representative area of urbanization rate area, Aksu area, rural population is large, agricultural population transfer pressure is serious, and other factors seriously hinder the development of Aksu city, however, the construction of small towns provides a good platform for Aksu's urbanization development.
\end{abstract}

\section{Introduction}

As early as 2015, premier Li Keqiang has proposed that China's urbanization should solve the problem, accelerate the construction of urbanization in all provinces, because the development of urbanization is conducive to improve labor productivity, it is beneficial to improve the quality of people, to increase and reduce investment, to resolve the crisis of excess capacity, and the significance of urbanization to economic and social development. In this paper, the author mainly discusses and studies the development and construction of urbanization in Aksu prefecture of Xinjiang.

\section{The importance of the development of urbanization in Aksu, Xinjiang}

General secretary Xi Jinping, at the second Xinjiang work conference, made clear that the overall goal of Xinjiang's work is social stability and long-term stability. Social stability is made up of two major aspects, the first is the stability of the material, the well-being of the people is the basis of our social stability, to ensure stability, we can continue to develop healthily. The second aspect is the ideological stability, we should not only let the people live and work, but also let them away from the extreme religious thought, adapt to modern society, accept modern culture and ideas. Marx said that the economic basis determines the superstructure. Only when people use the advanced production tools, embedded into the current production relations, can understand the modern culture, accept the modern concept. The small town built a platform to the modern city life transition, conducive to the local change of production and life style, so as to change the idea.

Many researchers believe that the rapid urbanization is the only way to the socialist urbanization in China, and the key effective way to solve the three rural issues, because the city is the polymerization and symbol of human civilization and productivity, urbanization is the trend of modern social development. More than two million poor people in Xinjiang are mainly distributed in the south of Xinjiang, which is directly related to the slow process of urbanization in the south of Xinjiang. Three years after the 2020, Xinjiang to achieve with the national people into a well - off, for Aksu region, is an not small challenge, Aksu area of the poor population is close to 400,000 people, most of the concentration in rural areas, broadening the source of income is an important measure to get rid of poverty, and the source of income is employment. For the mainland, the main way to transfer rural surplus labor is to other big cities, but for the farmers in south Xinjiang, the traditional concept of local employment, combined with the differences of language and customs, become the invisible fetters of labor mobility, so, to develop the characteristics of urbanization to 
solve the employment problem, increase the income of farmers is the best choice.

Urbanization leads to the development of urban and rural areas, which is a platform for agricultural products to go out of farmland and market, and is a barometer of supply and demand price of agricultural products, especially with the elimination of " five unification" in the autonomous region, farmers should improve their own ability and level according to their own actual and market demands. On the one hand, the economic function of agricultural and sideline products processing and trade distribution center of small towns makes farmers closer to the market, so they can understand the market demand and speed up the pace of supply and demand; On the other hand, the development of small towns transfer more farmers from the land, promote the intensive management of land, promote the industrialization of agriculture objectively, bring the market - oriented, the professional production with economic efficiency as the center, regulate the structure of production, and then through the social service, entrepreneurial management, circulation channel " internet of things + ", to establish a market-oriented agricultural structure

\section{An analysis of the current situation of urbanization in Aksu, Xinjiang}

Aksu prefecture of a city layout more scattered, from east to west more than $500 \mathrm{~km}$, township are small size, scattered power, resulting in the development of space and radiation areas small, the use of resources is insufficient, the attraction of the surrounding resources and funds is small, the city's radiation capacity is insufficient. Aksu area has a large number of rural population, but the township population is small, the agglomeration effect is insufficient, resulting in the lack of township functions. The third industry development degree is low, most of the township still have the business model of " go to market ", the township residents who are specialized in the tertiary industry are less.

Aksu area is located in the southern Xinjiang region, due to the constraints of geographical environment, resulting in lack of water resources, cultivated land area is limited, which makes Aksu area urbanization rate is low, the rural population is close to two million people, accounting for two thirds of the total population, combined with the high birth rate of rural population, resulting in insufficient land resources, lower than the average level in Xinjiang. More and more people, directly lead to the lower income of rural households, so the poverty alleviation work in Aksu area is more difficult, how to effectively and orderly transfer the rural surplus labor, this is the primary task of the Aksu urbanization development.

The per capita net income of farmers and herdsmen in Aksu area is basically the same as the average level of the whole region, but in the income proportion of the three industries, agricultural income accounts for about $90 \%$, especially the income of service industry is on the low level in the four regions of southern Xinjiang. There are two reasons for this situation: first, the land can also maintain the basic life of the family, the willingness of industrial transfer is relatively low; Secondly, due to the low level of culture, weak bilingual ability, lack of vocational skills, the ability of industrial transfer is insufficient, and the local industrial development is not matched, the tertiary industry is underdeveloped, less employment opportunities. These two points are cause and effect, and mutual influence, and finally form such a situation.

\section{Suggestions on the development of urbanization in Aksu, Xinjiang}

Industrialization is the first driving force of urbanization, and only the completion of industrialization in a region can stand up the backbone. First, we should strengthen education and train talents for the modernization of Aksu industry. Education is an important means to cultivate the basic quality of industrial workers. It is difficult for Aksu farmers to adapt to the life of industrial park, and to increase the putonghua course for primary and middle school students in the process of national quality education. To understand mandarin, and to have the courage to live and work in the city. In the student high school stage, should provide the best conditions to Aksu's students can upper high school, so that can accept the influence of industrial civilization and urban civilization, let the next generation of Aksu farmers have a strong desire to enjoy the city to 
facilitate life. Accelerate the establishment of the vocational and technical college system, let more senior high school graduates have the opportunity to go to college, learn a technology to meet the needs of the Aksu industrialization. If Aksu has enough to speak mandarin and skilled labour, then more companies will not need to bring workers from the mainland, but recruit local workers in Aksu. Secondly, give play to the advantages of Aksu industry, and strengthen the Aksu characteristic industry. Increase the investment of investment, make Aksu mineral development, dried fruit processing, fur processing and other eight traditional advantages industries. Then, establish the Aksu incubator, encourage the Aksu farmers to start a business.

Accelerate the construction of Aksu infrastructure, not only to provide convenience for Aksu residents, but also the development of Aksu urbanization, on the one hand, good infrastructure can drive the local population out, make full use of Xinjiang human resources, can bring new vitality and hope for Xinjiang. On the one hand, the construction of road traffic can enliven the local economy and promote economic development; On the other hand, accelerate the infrastructure construction, can facilitate more mainland tourists to Xinjiang, appreciate the rich tourism resources in Xinjiang, deepen the understanding of Xinjiang, attract investment.

Aksu's backwardness, mainly in the township this level of problems, we can concentrate resources to the development of township urbanization, let farmers into the township of the smallest city. Drawing on the experience of countries with better urbanization from abroad, we can know that the vast majority of the population is more willing to work and live in small cities, the vast majority of the population in France and Germany is not in big cities, but in small towns at the township level. First, the settlement and housing construction must be built in the local township government sites, in order to expand the size of township and town, to form a scale effect. Settlement and herdsmen's housing construction is not only to settle down the herdsmen from the mountain, And to enter the city, can not be down and enter the countryside, this way can not enjoy the convenient life of the city, farmers and herdsmen is not willing to buy such a house. Housing design, no longer the plane propulsion, this way can not form the population density, but upward to form buildings, this way can make the population density, and save land; At the same time, it is easy to form the market, promote the development of market and consumption, so as to promote employment. Secondly, the policy should be liberalized, allowing the transfer of land property rights and use rights of the township government, and the development of residential housing. Many farmers and herdsmen want to settle in their own hometown, the government takes into account: transfer them to their hometown more distant county or state, they live not used to, such as the formulation of policies, development of township small cities, allow the township government small town land property rights transfer or allow the developers to build commercial housing; Thus farmers and herdsmen build their own houses or purchase housing into small towns, increasing the size and density of the population, natural promotion of consumption and investment, in turn will promote the Aksu urbanization.

First, the scientific management of small vendors. For migrant workers who sell melons and snacks in cities, they can not take the policy of confiscation and expulsion simply and roughly. In this way, the enthusiasm of farmers into the city to do business, hindered the pace of urbanization in Aksu. But to scientific management of small vendors, as long as the certification can operate. For the vast majority of urban farmers, the first job is a stall, not even the right to a stall, they can not enter the city. Secondly, to provide good housing, work and study conditions for migrant workers and their children, to give them the same treatment as urban residents. Although there are still many problems in the construction of Aksu urbanization at this stage, it is believed that the rapid development of Aksu urbanization will be full of hope as long as the actual situation of Aksu, accelerate the industrialization and formulate policies to promote the Aksu rural urbanization.

\section{Conclusion}

The construction and development of urbanization in Aksu, Xinjiang, should give full play to the mode of urbanization with Chinese characteristics dominated by the government. Develop and 
change their own ideas, accelerate the development of Aksu industrial modernization, increase the investment of infrastructure in Aksu prefecture, implement the policy measures of urbanization development, and promote the development of urbanization in all regions of Xinjiang.

\section{Acknowledgements}

4)

Fund project: national philosophy and social science foundation project (project NO:12 X J Y 00

\section{References}

[1] Jianmin Long. Study on countermeasures of urbanization construction in Xinjiang autonomous prefecture[J]. Journal of Xinjiang vocational university, 2016(03):26-28.

[2] Min Yang. Analysis on the construction path of small towns with characteristics in Aksu prefecture[J]. Management Observer ,2017(17):188-189.

[3] Fugeng Wang. Thinking on advancing the process of urbanization in Aksu prefecture of Xinjiang[J]. Environmental market confidence guide,2014(03): 25-67.

[4] Gaoyang Yu, Yunfang Luo, Yiting Zhai. Study on the development and countermeasures of urbanization in Xinjiang[J]. Examination weekly publication,2015(48): 191-192.

[5] Yuan Xu, Xiaoyong Li, Xiaoling Zhu. On how to promote the urbanization of southern Xinjiang[J]. The study of modern state - owned enterprises, 2015(20)123-124. 